\title{
Origin and Fate of the Lysophosphatidylethanolamine in a Chain-forming Mutant (envC) of Escherichia coli
}

\author{
By G. P. F. MICHEL* AND J. STARKA \\ Laboratoire de Physiologie Microbienne, Groupement Scientifique de Luminy, 13288 Marseille \\ Cedex 9, France
}

(Received 18 October 1983; revised 28 November 1983)

\begin{abstract}
The role of phospholipid metabolism in the functioning of the bacterial envelope was investigated in the chain-forming Escherichia coli envC. Lysophosphatidylethanolamine (LPE) which accumulated in this strain during growth was indentified as the product of phosphatidylethanolamine (PE) hydrolysis by a phospholipase $A_{1}$, i.e. 2-acylLPE. Isotopically labelled LPE transferred into intact mutant and parent cells by liposome/bacteria interaction was rapidly reacylated to PE. However, in envC the final PE/LPE ratio was lower than that in the parent, thus showing that the fate of LPE is modified. Crude cell extracts degraded LPE to a lesser extent in envC than in the parent but were unable to promote reacylation activity under our experimental conditions. In both strains, the lysophospholipase activity was neither calciumdependent nor inhibited by the SH-group inhibitors $p$ HMB or $p$ CMPS, and hydrolysed 1acylLPE as well as 2-acylLPE. These results indicate the existence of a deacylation-reacylation cycle in $E$. coli and show that this cycle is perturbed in envC cells, especially at the lysophospholipase step.
\end{abstract}

\section{INTRODUCTION}

Lysophospholipids produced by phospholipase A present in the outer membrane of Escherichia coli are rapidly reacylated under normal conditions and do not accumulate in bacterial membranes (Homma et al., 1981; Proulx \& Van Deenen, 1966; Vos et al., 1978). However, this is not the case in the PM61 $(e n v C)$ strain, which exhibits lysophosphatidylethanolamine (LPE) accumulation during growth (Michel, 1979), in addition to antibiotic hypersensitivity and septation deficiency.

pldA mutants of $E$. coli, which are defective in phospholipase A, grow almost normally. It was proposed, therefore, that this enzyme is not essential, at least in laboratory conditions (Ohki et al., 1972; Raetz, 1978). However, Hardaway \& Buller (1979) showed that the breakdown of the permeability barrier of $E$. coli towards actinomycin D is related to activation of phospholipase A.

The micellar organization of lysophospholipids can create unstable zones in the envelope structure (Cullis \& De Kruijff, 1979; Luzzati et al., 1968). Under certain conditions, lysophospholipids are bactericidal (Duckworth et al., 1974), haemolytic (Bierbaum et al., 1979) and inhibit enzyme activity (Mookerjea, 1979). Conversely, as suggested by Gerritsen et al. (1979), lysophospholipids can correct defective interaction between some proteins and some phospholipids. This idea emerged from the observation that introduction of conical lipids (Cullis \& De Kruijff, 1978, 1979), like unsaturated phosphatidylethanolamine (PE) or unsaturated lysophosphatidylcholine, into liposomes consisting of phosphatidylcholine and glycophorin established a permeability barrier to dysprosium chloride (Gerritsen et al., 1979).

\footnotetext{
Abbreviations: LPE, lysophosphatidylethanolamine; PE, phosphatidylethanolamine; $p$ HMB, $p$-hydroxymercuribenzoate; $p$ CMPS, $p$-chloromercuriphenylsulphonate.
} 
Consequently, it is possible that LPE accumulation in PM61 may have a physiological significance and could be related in some manner to envelope perturbation.

This suggestion is supported by an earlier observation that there is a relation between LPE accumulation and the increase in chain length of strain PM61. Conversion of this mutant from the chain form to individual rods could be induced by addition of sugars to increase the osmolarity of the growth medium, or by decreasing the growth temperature. This partial phenotypic correction was accompanied by a decrease in cellular LPE content, although it was not lowered to the level of the parent strain (G. P. F. Michel, unpublished results).

Because little is known about the physiological role of phospholipid metabolism in envelope function, there is no doubt that the envC mutant, which is characterized by changes in envelope properties and phospholipid metabolism, is a useful tool for the study of the involvement of membrane-phospholipids in cellular events, such as septation and permeability. By taking this approach, we tried as a first step to elucidate the origin of the perturbation of phospholipid metabolism in envC which leads to LPE accumulation.

In a previous report, we showed that labelled PE transferred by means of liposomes into intact cells is hydrolysed to LPE more rapidly in PM61 than in its parent, P678; this result was interpreted to be a consequence of phospholipase A activation (Michel \& Starka, 1979). The present paper describes results showing that the fate of LPE is modified in PM61, and suggests that three different alterations of phospholipid metabolism could be involved in 2-acylLPE accumulation in this strain.

\section{METHODS}

Bacterial strains, media and culture conditions. The origin and characteristics of E. coli P678 env $C^{+}$and PM61 envC have been described previously (Rodolakis et al., 1974). S15 pldA ${ }^{+}$and $\$ 17$ pldA (phospholipase A deficient) were described by Abe et al. (1974) and Ohki et al. (1972). Bacteria were grown at $37^{\circ} \mathrm{C}$ in a gyratory shaker on complete medium containing $\left(1^{-1}\right): 5 \mathrm{~g}$ tryptose (Difco), $5 \mathrm{~g}$ yeast extract (Difco) and $8 \mathrm{~g} \mathrm{NaCl}$. Optical density was measured at $450 \mathrm{~nm}$.

Extraction and analysis of phospholipids. Phospholipids were extracted with chloroform/methanol from rapidly chilled cells and separated by thin-layer chromatography as described previously (Starka \& Moravova, 1970). The portions of silica gel containing individual $\left[2-{ }^{3} \mathrm{H}\right]$ glycerol-labelled phospholipids were scraped off and transferred to scintillation vials containing $0.4 \mathrm{ml}$ water and $5 \mathrm{ml}$ Ready-Solv MP (Beckman) in order to minimize quenching due to silica gel. Each vial was then placed in a water-bath sonicator for $5 \mathrm{~min}$ before the radioactivity was estimated. Total phospholipid phosphorus was determined as described by Ames \& Dubin (1960).

Fatty acid analysis. Fatty acid methyl esters prepared with boron trifluoride in methanol were analysed by gasliquid chromatography on a BDS column $2 \mathrm{~m}$ long (Interchim, France) using a Varian 1440 series chromatograph equipped with a flame-ionization detector. The temperatures of the injector, detector and column were respectively $235^{\circ} \mathrm{C}, 235^{\circ} \mathrm{C}$ and $185^{\circ} \mathrm{C}$. Identification of fatty acids was made by comparison with authentic standards. Cyclopropane fatty acids were identified after hydrogenation in acetic acid (Kaneshiro \& Marr, 1961).

Phospholipid isolation. Total lipid extracts were separated from neutral lipids by silicic acid column chromatography. Neutral lipids were eluted with chloroform and adsorbed phospholipids were eluted with methanol. Individual phospholipids were separated and purified by thin-layer chromatography on preparative plates (Merck 5745) developed successively in chloroform/methanol/ammonia/water $(70: 30: 4: 2$, by vol.), chloroform/methanol/water $(65: 25: 4$, by vol.) and chloroform/methanol/acetic acid $(65: 25: 9$, by vol.). Silica gel bands containing the phospholipids were scraped off, dispersed by sonication in a water-bath and the phospholipids eluted sequentially with chloroform containing increasing proportions of methanol, and finally with methanol alone. At each elution step, silica gel was recovered by centrifugation $\left(1500 \mathrm{~g}, 10 \mathrm{~min}, 20^{\circ} \mathrm{C}\right)$ and the supernatant fluid containing the phospholipids was evaporated to dryness.

Hydrolysis by phospholipase $A_{2}$. Labelled LPE or PE extracted from PM61 grown on complete medium containing $2 \mu \mathrm{Ci}$ [ ${ }^{32} \mathrm{P}$ ]phosphate $\mathrm{ml}^{-1}\left(74 \mathrm{kBq} \mathrm{ml}{ }^{-1}\right)$ was incubated at $37^{\circ} \mathrm{C}$ for $12 \mathrm{~h}$ with phospholipase $\mathrm{A}_{2}$ (Naja naja, Sigma). The incubation mixture contained $70 \mathrm{nmol}$ phospholipid in $100 \mu \mathrm{l}$ methanol and $1 \mathrm{ml}$ HEPES buffer, $\mathrm{pH}$ 8.0. The mixture was dispersed by sonication for $30 \mathrm{~s}$ in a water-bath sonicator and 10 units of phospholipase $\mathrm{A}_{2}$ and $5 \mathrm{mM}-\mathrm{CaCl}_{2}$ (final concentration) were added. The reaction was stopped by successive additions of $2 \mathrm{ml}$ methanol, $2 \mathrm{ml}$ chloroform and $0.8 \mathrm{ml}$ distilled water. The upper phase was removed and shaken with $2 \mathrm{ml}$ chloroform for a second lipid extraction. The two chloroform phases were mixed, evaporated to dryness, dissolved in a small volume of chloroform and chromatographed on thin-layer silica gel plates (Merck 5721) 
using chloroform/methanol/acetic acid $(65: 25: 9$, by vol.) as solvent. The phospholipids were detected by autoradiography.

Fate of exogenous LPE integrated into cells. Bacteria harvested from the exponential phase of growth were suspended in $2 \mathrm{ml} 10 \mathrm{mM}-H E P E S$ buffer (pH 7.5) and incubated for $60 \mathrm{~min}$ with $2 \mathrm{ml}$ liposomes in the presence of $20 \mathrm{mM}^{-\mathrm{CaCl}_{2}}$ (final concentration). Liposomes were prepared with unlabelled total phospholipids extracted from PM61 and $\left.{ }^{3} \mathrm{H}\right]$ LPE in a ratio $1: 2 \cdot 5$ (based on phosphorus determination). The liposome-cell interaction was interrupted by addition of $20 \mathrm{~mm}$-EDTA and the bacteria were separated from non-integrated liposomes by centrifugation through $10 \%(\mathrm{w} / \mathrm{v})$ Ficoll in $10 \mathrm{~mm}$-HEPES ( $\mathrm{pH} 7 \cdot 5$ ), as described by Jones \& Osborn (1977). These cells were washed successively with prewarmed $1 \mathrm{mM}-\mathrm{MgCl}_{2}$ in $10 \mathrm{mM}-\mathrm{HEPES}(\mathrm{pH} 7 \cdot 5)$ and with complete medium before being suspended in $150 \mathrm{ml}$ of prewarmed complete medium and grown at $37^{\circ} \mathrm{C}$ in a gyratory shaker. Samples were withdrawn at intervals; phospholipids were extracted directly from the cells, chromatographed and the radioactivity of individual phospholipids measured as described above.

Lysophospholipase assays. Bacteria in the exponential growth phase were harvested $\left(7000 \mathrm{~g}, 5 \mathrm{~min}, 4^{\circ} \mathrm{C}\right)$, washed with cold $10 \mathrm{~mm}-\mathrm{HEPES}$ containing $1 \%(\mathrm{w} / \mathrm{v}) \mathrm{NaCl}(\mathrm{pH} 7.5)$ and suspended in $10 \mathrm{mM}-\mathrm{HEPES}(\mathrm{pH} 7.5)$. The cells were sonicated in ice with a Sonifier B-12 (Branson Sonic Power Co., Soest, The Netherlands) for five periods of $30 \mathrm{~s}$ at $45 \mathrm{~W}$. Unbroken cells were removed by centrifugation $\left(1500 \mathrm{~g}, 10 \mathrm{~min}, 4^{\circ} \mathrm{C}\right)$ and the supernatant (crude extract) was used as a source of enzyme. The incubation mixture consisted of $0.2 \mathrm{ml}$ LPE dispersion prepared by sonication in a water-bath sonicator $(30 \mathrm{~s})$ in either $50 \mathrm{~mm}$-Tris/maleate buffer (pH 6.0) for 2acylLPE, or in $10 \mathrm{mM}$-HEPES buffer ( $\mathrm{pH} \mathrm{7.5)} \mathrm{for} \mathrm{1-acylLPE,} \mathrm{and} 0.5 \mathrm{ml}$ crude extract. The reaction was carried out at $37^{\circ} \mathrm{C}$ for $60 \mathrm{~min}$ and stopped by phospholipid extraction. The radioactivity of individual phospholipids recovered on silica gel plates after thin-layer chromatography was determined.

$S H$-group inhibitor treatment. Cells harvested from the exponential growth phase were suspended in $10 \mathrm{ml}$ $10 \mathrm{mM}$-HEPES buffer (pH 7.5) containing either $1 \mathrm{mM}$ - $p$-hydroxymercuribenzoate (Fluka, Buchs, Switzerland) or $1 \mathrm{mM}$-p-chloromercuriphenylsulphonate (Sigma) and incubated at $37^{\circ} \mathrm{C}$ for $30 \mathrm{~min}$.

\section{RESULTS}

\section{Identification of the LPE from PM61}

Analysis of the molecular species of LPE extracted and isolated from early stationary phase PM61 cells showed an enrichment in unsaturated and cyclopropane fatty acids as compared to the PE and 1-acylLPE obtained after phospholipase $A_{2}$ treatment of PE (Table 1). Considering the position specificity of fatty acids in the phospholipid molecules, i.e. saturated fatty acids in position 1 and unsaturated and cyclopropane fatty acids in position 2 (Raetz, 1978), such a result suggests the presence of a 2-acylLPE in PM61. This was confirmed by showing that LPE isolated from ${ }^{32} \mathrm{P}$-labelled PM61 cells was hydrolysed by the phospholipase $\mathrm{A}_{2}$ of Naja naja (Fig. 1) indicating the presence of a 2-acylLPE, produced in PM61 by a phospholipase $A_{1}$.

Table 1. Fatty acid composition of lysophosphatidylethanolamine isolated from PM61 (envC) and of 1-acyllysophosphatidylethanolamine obtained from phosphatidylethanolamine after phospholipase $A_{2}$ treatment

The results are mean values from two experiments. tr, trace.

\begin{tabular}{|c|c|c|c|}
\hline \multirow[b]{2}{*}{ Fatty acid } & \multicolumn{3}{|c|}{$\begin{array}{l}\text { Percentage of total } \\
\text { fatty acid }{ }^{*} \text { in: }\end{array}$} \\
\hline & LPE & $\mathrm{PE}+\mathrm{A}_{2}{ }^{*}$ & $\mathrm{PE}$ \\
\hline $14: 0$ & $3 \cdot 0$ & $4 \cdot 2$ & 5.4 \\
\hline $16: 0$ & $19 \cdot 0$ & $83 \cdot 5$ & 53.9 \\
\hline $16: 1$ & $40 \cdot 0$ & $4 \cdot 0$ & $27 \cdot 0$ \\
\hline$C_{17} \Delta$ & $28 \cdot 0$ & $5 \cdot 2$ & 9.3 \\
\hline $18: 0$ & $\operatorname{tr}$ & 0.5 & $\operatorname{tr}$ \\
\hline $18: 1$ & $10 \cdot 0$ & $2 \cdot 5$ & $4 \cdot 4$ \\
\hline Unsaturated (U) & $50 \cdot 0$ & $6 \cdot 5$ & $31 \cdot 4$ \\
\hline Saturated (S) & $22 \cdot 0$ & $88 \cdot 2$ & $59 \cdot 3$ \\
\hline Cyclopropane $(\mathrm{Cy})$ & $28 \cdot 0$ & $5 \cdot 2$ & $9 \cdot 3$ \\
\hline$(\mathrm{Cy}+\mathrm{U}) / \mathrm{S}$ & $3 \cdot 5$ & $0 \cdot 1$ & 0.7 \\
\hline
\end{tabular}

* PE hydrolysed by phospholipase $\mathrm{A}_{2}$. 


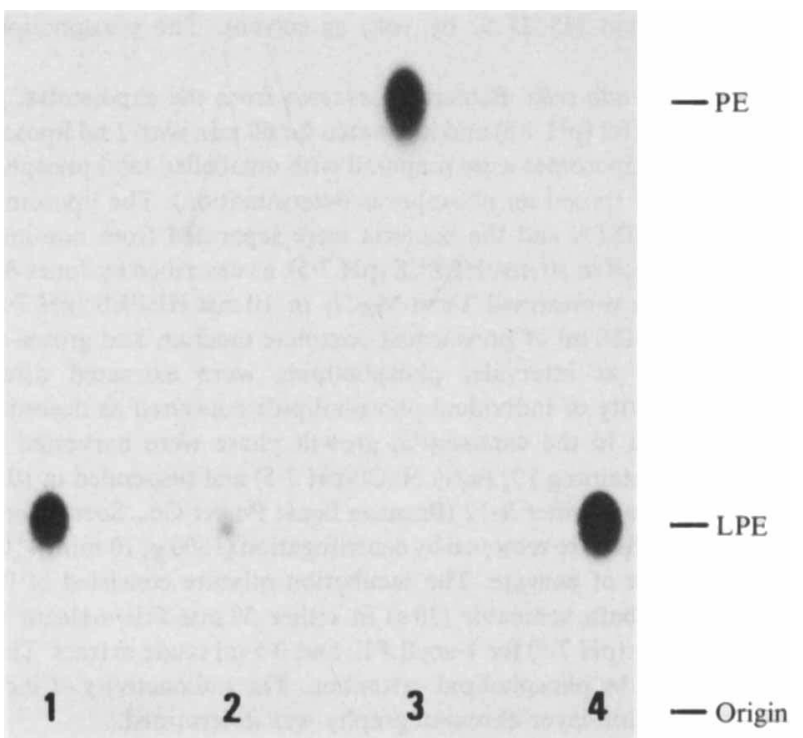

Fig. 1. Hydrolysis of lysophosphatidylethanolamine and phosphatidylethanolamine by phospholipase $A_{2}$. [ $\left.{ }^{32} \mathrm{P}\right] \mathrm{LPE}$ and [ $\left.{ }^{32} \mathrm{P}\right] \mathrm{PE}$ isolated from PM61 cells were incubated with phospholipase $\mathrm{A}_{2}$ as indicated in Methods. After incubation, the phospholipids were extracted, separated by thin-layer chromatography and detected by autoradiography. 1, Untreated LPE; 2 , hydrolysed LPE; 3, untreated $\mathrm{PE}$; 4, hydrolysed PE.

\section{Effect of SH-group inhibitors on LPE accumulation}

Large quantities of LPE for analytical use were isolated by incubating bacteria in HEPES buffer containing an SH-group inhibitor, $p \mathrm{HMB}$ or $p \mathrm{CMPS}$, at $37^{\circ} \mathrm{C}$. In the presence of $p \mathrm{HMB}$, we found that LPE accumulation in P678 and PM61 attained, respectively, $8.6 \%$ and $12.4 \%$ of the total phospholipid content (Table 2). Similar results, not shown here, were obtained with $p$ CMPS. Moreover, the LPE obtained after $p$ HMB treatment was a 2-acylLPE, as indicated by its susceptibility to phospholipase $\mathbf{A}_{2}$ and its high proportion of unsaturated fatty acids (data not shown). The content of unsaturated fatty acids in phosphatidylglycerol, diphosphatidylglycerol, and particularly phosphatidylethanolamine is higher in untreated PM61 than in P678. These differences are not due to the incubation of cells in the HEPES buffer, since phospholipids directly extracted from PM61 are also more unsaturated than those of P678 (data not shown). It should be noted that the treatment of bacteria with SH-group inhibitors could also be a useful test for the detection of phospholipase A-deficient strains. Indeed, the mutant S17 (pldA), unlike its parent strain $\mathrm{S} 15$, when incubated in the presence of $p \mathrm{HMB}$ produced no detectable LPE (unpublished result).

Fate of the liposomal LPE integrated into cells

Exogenous LPE was integrated into cells via liposome-cell interaction. The increase of the $\left[{ }^{3} \mathrm{H}\right] \mathrm{PE}:\left[{ }^{3} \mathrm{H}\right] \mathrm{LPE}$ ratio in the cells showed that liposomal LPE was converted to PE by a reacylation process (Table 3). Although this ratio was higher in P678 than in PM61, it is not clear what kind of process is altered in the mutant, since reacylation and lysophospholipase activities take place simultaneously in intact cells of both strains.

\section{LPE degradation by P678 and PM61 cell extracts}

Incubation of LPE with crude cell extracts did not induce conversion of LPE to PE (i.e. reacylation) under our experimental conditions. Deacylation was assessed by hydrolysis of LPE: 2-acylLPE was hydrolysed faster in P678 than in PM61. This hydrolysis was slightly stimulated 
Table 2. Effect of p-hydroxymercuribenzoate on the phospholipid composition of P678 and PM61

Lysophosphatidylserine (LPS), lysophosphatidylethanolamine (LPE), phosphatidylserine (PS), phosphatidylethanolamine (PE), phosphatidylglycerol (PG) and diphosphatidylglycerol (DPG) were extracted from untreated cells (Expt 1), from cells incubated for $30 \mathrm{~min}$ in $10 \mathrm{mM}$-HEPES pH 7.5 at $0{ }^{\circ} \mathrm{C}$ (Expt 2) or at $37^{\circ} \mathrm{C}$ (Expt 3), and from cells incubated as in Expt 3 but with 1 mM-phydroxymercuribenzoate (Expt 4). In each case the results represent mean values from three experiments. tr, trace; -, not detectable.

\begin{tabular}{|c|c|c|c|c|c|c|c|}
\hline \multirow[b]{2}{*}{ Strain } & \multirow[b]{2}{*}{ Expt } & \multicolumn{6}{|c|}{ Percentage of total $\left[{ }^{32} \mathrm{P}\right]$ phospholipids } \\
\hline & & LPS & LPE & PS & PE & PG & DPG \\
\hline P678 & $\begin{array}{l}1 \\
2 \\
3 \\
4\end{array}$ & $\begin{array}{l}- \\
- \\
- \\
\operatorname{tr}\end{array}$ & $\begin{array}{l}- \\
\operatorname{tr} \\
1 \cdot 9 \\
8.6\end{array}$ & $\begin{array}{l}- \\
- \\
- \\
-\end{array}$ & $\begin{array}{l}74 \cdot 4 \\
74 \cdot 3 \\
72 \cdot 3 \\
65 \cdot 8\end{array}$ & $\begin{array}{r}14.5 \\
14 \cdot 8 \\
8.7 \\
13 \cdot 3\end{array}$ & $\begin{array}{l}11 \cdot 1 \\
10 \cdot 9 \\
17 \cdot 1 \\
12 \cdot 3\end{array}$ \\
\hline PM61 & $\begin{array}{l}1 \\
2 \\
3 \\
4\end{array}$ & $\begin{array}{l}- \\
- \\
\text { tr } \\
-\end{array}$ & $\begin{array}{r}1 \cdot 7 \\
2.1 \\
5.5 \\
12.4\end{array}$ & $\begin{array}{l}\mathrm{tr} \\
\mathrm{tr} \\
\mathrm{tr} \\
\mathrm{tr}\end{array}$ & $\begin{array}{l}72 \cdot 7 \\
72 \cdot 8 \\
71 \cdot 4 \\
64 \cdot 1\end{array}$ & $\begin{array}{r}11.0 \\
10.0 \\
4.8 \\
8.3\end{array}$ & $\begin{array}{l}14 \cdot 6 \\
15 \cdot 1 \\
18 \cdot 3 \\
15 \cdot 2\end{array}$ \\
\hline
\end{tabular}

Table 3. Fate of liposomal lysophosphatidylethanolamine integrated into P678 and PM61 cells

Cells were grown and exposed to liposomes containing $\left[{ }^{3} \mathrm{H}\right] \mathrm{LPE}$ as described in Methods. Samples were withdrawn immediately after resuspension in growth medium, and after $60 \mathrm{~min}$ and $12 \mathrm{~h}$ of incubation at $37^{\circ} \mathrm{C}$. Cellular phospholipids were extracted and analysed by thin-layer chromatography. The results are mean values from two experiments for P678 and three for PM61; the values in parentheses represent the $\mathrm{PE} / \mathrm{LPE}$ ratios.

\begin{tabular}{|c|c|c|c|c|}
\hline \multirow[b]{2}{*}{ Strain } & \multirow[b]{2}{*}[{}^{3}\mathrm{H}]{ Phospholipid } & \multicolumn{3}{|c|}{$\begin{array}{l}\text { Radiolabelled PE and LPE } \\
\text { [nmol (mg cell protein) })^{-1} \text { ] at: }\end{array}$} \\
\hline & & 0 & $60 \mathrm{~min}$ & $12 \mathrm{~h}$ \\
\hline P678 & $\begin{array}{l}\text { PE } \\
\text { LPE }\end{array}$ & $\begin{array}{c}12 \cdot 1 \\
1 \cdot 0 \\
(12 \cdot 0)\end{array}$ & $\begin{array}{r}4.4 \\
0.4 \\
(11.0)\end{array}$ & $\begin{array}{r}1.35 \\
0 \cdot 11 \\
(12.0)\end{array}$ \\
\hline PM61 & $\begin{array}{l}\text { PE } \\
\text { LPE }\end{array}$ & $\begin{array}{c}22 \cdot 0 \\
9 \cdot 6 \\
(2 \cdot 3)\end{array}$ & $\begin{array}{c}14 \cdot 1 \\
5 \cdot 3 \\
(2 \cdot 7)\end{array}$ & $\begin{array}{r}2.25 \\
0.45 \\
(5.0)\end{array}$ \\
\hline
\end{tabular}

Table 4. Hydrolysis of lysophosphatidylethanolamines by cell homogenates of P678 and PM61

Supernatants of sonicated cells were incubated either with 2-acylLPE or with 1-acylLPE (40 nmol) at $37^{\circ} \mathrm{C}$ for $60 \mathrm{~min}$. Where indicated, the reaction mixture contained $10 \mathrm{mM}-\mathrm{CaCl}_{2}$. Undigested substrate was separated by thin-layer chromatography and its radioactivity determined. Results are mean values from two experiments with duplicate samples.

\begin{tabular}{|c|c|c|c|c|c|c|}
\hline \multirow[b]{3}{*}{ Strain } & \multicolumn{6}{|c|}{ Percentage hydrolysis (mg protein) $)^{-1} \mathrm{~h}^{-1}$} \\
\hline & \multicolumn{4}{|c|}{ 2-acylLPE } & \multicolumn{2}{|c|}{ 1-acylLPE } \\
\hline & $-\mathrm{Ca}^{2+}$ & $+\mathrm{Ca}^{2+}$ & $-p \mathrm{HMB}$ & $+p \mathrm{HMB}^{*}$ & $-\mathrm{Ca}^{2+}$ & $+\mathrm{Ca}^{2+}$ \\
\hline P678 & $12 \cdot 4$ & $14 \cdot 0$ & $9 \cdot 2$ & $9 \cdot 2$ & $9 \cdot 0$ & $10 \cdot 2$ \\
\hline PM61 & $6 \cdot 7$ & $8 \cdot 0$ & $6 \cdot 0$ & $7 \cdot 4$ & $4 \cdot 5$ & $5 \cdot 0$ \\
\hline
\end{tabular}

* Cells preincubated in $1 \mathrm{mM}$-p-hydroxymercuribenzoate $(p \mathrm{HMB})$ for $10 \mathrm{~min}$ at $37^{\circ} \mathrm{C}$ were sonicated and the supernatants incubated with $16 \mathrm{nmol}$ substrate in presence of $p \mathrm{HMB}$.

by calcium, although this cation was not absolutely required (Table 4). Furthermore, LPE hydrolysis was not inhibited by $p H M B$ and it was not specific for the 2-acylLPE, since 1-acylLPE prepared from PE after phospholipase $A_{2}$ treatment was hydrolysed as well as 2-acylLPE. However, 1-acylLPE was hydrolysed less efficiently by PM61 than by P678 extracts. 
These observations would mean that either only one enzyme participates in the hydrolysis of 1and 2-acylLPE, or if two distinct enzymes are involved, both activities are modified in PM61.

\section{DISCUSSION}

Lysophospholipids, and especially LPE, do not accumulate in more than trace amounts in growing cells of $E$. coli because they are quickly utilized as substrates for enzyme reactions involving reacylase and lysophospholipase activities (Doi et al., 1972; Doi \& Nojima, 1975; Homma et al., 1981). Together with phospholipase A these enzyme activities constitute a deacylation-reacylation cycle, which is shown schematically in Fig. 2. Phospholipase $A_{1}$ causes degradation of PE to LPE (step 1) which can be either hydrolysed to glycerylphosphorylethanolamine (GPE) and fatty acid (FA) by a lysophospholipase (step 2) or converted to PE by a reacylase activity (step 3 ). It should be pointed out that the reacylation process leading to the neosynthesis of PE from LPE could be achieved either by addition of a free fatty acid or by transfer of a fatty acid from a phospholipid or even a lysophospholipid (transacylation) to LPE. Perturbation of the cycle at any step could induce a modification of the phospholipid composition and, as in PM61, accumulation of LPE.

For this reason, studies on the functioning of the deacylation-reacylation cycle are important for the understanding of the role of phospholipid metabolism in cellular physiology. One can imagine that this cycle is involved in the rearrangement of cellular components following perturbation, and in the control of membrane growth.

In a previous paper (Michel \& Starka, 1979) we showed that PE was converted to LPE more rapidly in PM61 than in its parent P678. This led us to suggest that LPE accumulation is the consequence of an abnormal phospholipase $A_{1}$ activation in PM61. However, LPE accumulation could also involve other enzyme systems using LPE as substrate, i.e. reacylase and lysophospholipase. Indeed, if one considers the deacylation-reacylation cycle (Fig. 2), LPE accumulation might result from phospholipase $A_{1}$ activation (step 1), lysophospholipase deficiency (step 2) or reacylase deficiency (step 3).

It has been shown that in $E$. coli, LPE degradation can be achieved either by the lysophospholipase activity of the detergent-resistant phospholipase A which is calciumdependent (Nishijima et al., 1977) or by a specific lysophospholipase showing no dependence on calcium (Doi \& Nojima, 1975). We found that LPE hydrolysis by crude cell extracts of the two strains studied is neither calcium dependent nor inhibited by SH-group inhibitors and acts as well on 1-acylLPE as on 2-acylLPE. Therefore, it seems likely that the enzyme activity detected in our experiments is probably a specific lysophospholipase rather than a lysophospholipase activity of the detergent-resistant phospholipase A. Furthermore, it cannot be excluded that in $E$. coli, a single enzyme is responsible for the hydrolysis of the 1- and 2-acyl ester bonds in lysophospholipid molecules. This possibility is also supported by the results of Doi \& Nojima (1975).

Although we found diminished lysophospholipase activity in PM61, it is still not clear if LPE

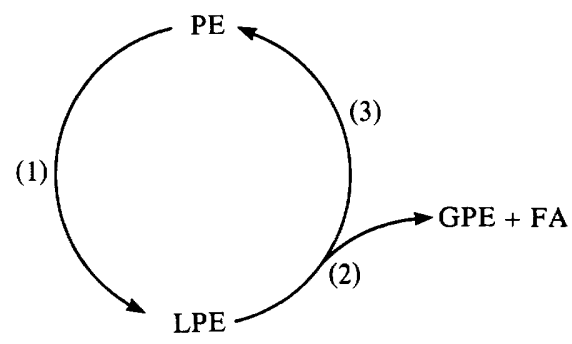

Fig. 2. Deacylation-reacylation cycle in E. coli. PE, phosphatidylethanolamine; LPE, lysophosphatidylethanolamine; FA, fatty acid; GPE, glycerylphosphorylethanolamine. (1) Phospholipase, (2) lysophospholipase, (3) reacylase. 
accumulation is the result of phospholipase $A_{1}$ activation and/or lysophospholipase and reacylase deficiencies. It would be necessary to block two of the three steps of the deacylationreacylation cycle to test each of the possibilities, at least for steps (1) and (3). Nevertheless, our results show conclusively that the fate of LPE is modified in envC since the $\left[{ }^{3} \mathrm{H}\right] \mathrm{PE}:\left[{ }^{3} \mathrm{H}\right] \mathrm{LPE}$ ratio found in growing bacteria having integrated exogenous $\left[{ }^{3} \mathrm{H}\right] \mathrm{LPE}$ via liposome-cell interaction is lower in the mutant than in the parent.

Further studies will be required to check if the apparent deficiency of the deacylationreacylation cycle in PM61 is directly involved in envelope alterations of this mutant, or if a regulatory control system triggered by envelope alterations acts on the enzyme activities involved in this cycle, in order to provide for some proteins a lipid environment more favourable to their functions. According to the hypothesis of Gerritsen et al. (1979), the presence of unsaturated lysophospholipid and the increase of unsaturated PE in PM61 could be indicative of the second possibility.

We are currently pursuing other studies in order to clarify the relationship of $e n v C$ and LPE accumulation. Transduction of the mutant gene envC out of PM61 by P1 phage grown on CBK 286 cysE:: $\operatorname{Tn} 5$ led to disappearance of chains and decrease of LPE. These preliminary results suggest that $e n v C$ could be involved both in cellular division and in the functioning of the deacylation-reacylation cycle.

We are grateful to B. Entressangles and D. Karibian for helpful advice and discussions.

\section{REFERENCES}

Abe, M., OKamoto, N., DoI, O. \& Nojima, S. (1974). Genetic mapping of the locus for detergent-resistant phospholipase A (pldA) in E. coli K12. Journal of Bacteriology 119, 543-546.

AMES, B. \& DUBIN, D. T. (1960). Role of polyamines in the neutralisation of bacteriophage DNA. Journal of Biological Chemistry 235, 769-775.

Bierbaum, T. J., Bouma, S. R. \& Huestis, W. J. (1979). A mechanism of erythrocytes lysis by lysophosphatidylcholine. Biochimica et biophysica acta 555, 102110.

Cullis, P. R. \& De KruijfF, B. (1978). Polymorphic phase behaviour of lipid mixtures as detected by ${ }^{31} \mathrm{P}$ NMR. Evidence that cholesterol may destabilize bilayer structure in membrane systems containing phosphatidylethanolamine. Biochimica et biophysica acta 551, 248-259.

Cullis, P. R. \& De KruijfF, B. (1979). Lipid polymorphism and the functional roles of lipids in biological membranes. Biochimica et biophysica acta 559, 399-420.

Dol, O. \& Nojima, S. (1975). Lysophospholipase of $E$. coli. Journal of Biological Chemistry 250, 5208-5214.

DoI, O.\& Nojima, S. (1976). Nature of E. coli mutants deficient in detergent-resistant and/or detergentsensitive phospholipase A. Journal of Biochemistry 80, $1247-1248$.

DoI, O., OHKI, M. \& NoJima, S. (1972). Two kinds of phospholipase A and lysophospholipase in Escherichia coli. Biochimica et biophysica acta 260, 244-258.

DuCKWORTH, D. H., BeVers, E., VerKLEIJ, A. J., OP DEN KAMP, J. A. F. \& VAN DeEnen, L. L. M. (1974). Action of phospholipase $A_{2}$ and phospholipase $C$ on E. coli. Archives of Biochemistry and Biophysics 165, 379-387.

Gerritsen, W. J., van Zoelen, E. J. J., VerkleiJ, A. J., De Kruiff, B. \& Van Deenen, L. L. M. (1979). A ${ }^{13}$ C-NMR method for determination of the transbilayer distribution of phosphatidylcholine in large unilamellar, protein free and protein containing vesicles. Biochimica et biophysica acta 551 , 248-259.

Hardaway, K. L. \& Buller, C. S. (1979). Effect of EDTA on phospholipid and outer membrane function in E. coli. Journal of Bacteriology 137, 62-68.

Homma, H., Nishijima, M., Kobayashi, T., OKuyama, H. \& Nojima, S. (1981). Incorporation and metabolism of 2-acyllysophospholipid by $E$. coli $\mathrm{K} 12$. Biochimica et biophysica acta $663,1-13$.

JONEs, N. C. \& OsBoRN, M. J. (1977). Interaction of $S$. typhimurium with phospholipid vesicles. Incorporation of exogenous lipids into intact cells. Journal of Biological Chemistry 252, 7398-7404.

KANEShIRo, T. \& MARR, A. G. (1961). cis-9,10Methylenehexadecanoic acid from the phospholipids of E. coli. Journal of Biological Chemistry 236, 2615-2619.

LUZzati, V., Gulik KrzYwicki, T. \& TardieU, A. (1968). Polymorphism of lecithins. Nature, London 218, 1031-1034.

MicheL, G. P. F. (1979). The changes in cell size and phospholipid composition during growth of a chainforming envC mutant of $E$. coli. FEBS Letters 100 , 258-260.

Michel, G. P. F. \& Starka, J. (1979). Phospholipase A activity with integrated phospholipid vesicles in intact cells of an envelope mutant of $E$. coli. FEBS Letters 108, 261-265.

MoOKerJeA, S. (1979). Effect of lysolecithin in solubilizing membrane-bound galactosyltransferases. Canadian Journal of Biochemistry 57, 66-71.

Nishijima, M., Nakaike, S., Tamori, Y. \& Nojima, S. (1977). Detergent-resistant phospholipase A of $E$. coli K12. Purification and properties. European Journal of Biochemistry 73, 115-124.

Ohki, M., DoI, O. \& NoJima, S. (1972). Mutants of $E$. 
coli $\mathrm{K} 12$ deficient for detergent-resistant phospholipase A. Journal of Bacteriology 110, 864-869.

Proulx, P. R. \& Van Deenen, L. L. M. (1966). Acylation of lysophospholipids by $E$. coli. Biochimica et biophysica acta 125, 591-593.

RAETZ, C. R. H. (1978). Enzymology, genetics and regulation of membrane phospholipid synthesis in $E$. coli. Microbiological Reviews 42, 614-659.

Rodolakis, A., Casse, F. \& STARKa, J. (1974). Morphological mutant of E. coli K12. Molecular and General Genetics 130, 177-181.

SCandella, C. J. \& Kornberg, A. (1971). A membrane-bound phospholipase purified from $E$. coli. Biochemistry 10, 4447-4456.
Starka, J. \& Moravova, J. (1970). Phospholipids and cellular division of Escherichia coli. Journal of General Microbiology 60, 251-257.

TAMORI, Y., Nishijima, M. \& Nojima, S. (1979). Properties of purified detergent-resistant phospholipase $A$ of $E$. coli. Inactivation and protection with detergents and phospholipids. Journal of Biochemistry 86, 1129-1138.

Vos, M. M., OP DEN KAMP, J. A. F., Bequerdite Quagliata, S. \& Elsbach, P. (1978). Acylation of monoacylglycerophosphoethanolamine in the inner and the outer membranes of the envelope of an $E$. coli $\mathrm{K} 12$ strain and its phospholipase A-deficient mutant. Biochimica et biophysica acta 508, 165-173. 